\title{
A Good Policy for Guaranteed Safe Practice of Complementary and Alternative Medicine, Usage of Disposable Cupping Cups
}

\author{
Tae-Hun Kim ${ }^{1}$ and Jung Won Kang ${ }^{2}$ \\ ${ }^{1}$ Korean Medicine Clinical Trial Center, Korean Medicine Hospital, Kyung Hee University, Seoul 130-872, Republic of Korea \\ ${ }^{2}$ Department of Acupuncture \& Moxibustion, College of Korean Medicine, Kyung Hee University, Seoul 130-872, Republic of Korea \\ Correspondence should be addressed to Jung Won Kang; doctorkang@naver.com
}

Received 20 October 2014; Accepted 14 April 2015

Academic Editor: Olumayokun A. Olajide

Copyright (c) 2015 T.-H. Kim and J. W. Kang. This is an open access article distributed under the Creative Commons Attribution License, which permits unrestricted use, distribution, and reproduction in any medium, provided the original work is properly cited.

This is a comment on "Addendum: Safety Standards for Gua Sha (Press-Stroking) and Ba Guan (Cupping)" [1]. Interventions of complementary and alternative medicine (CAM) are facing huge challenges whether their effectiveness and safety can be supported by concrete evidence. Although CAM is widely used and takes considerable charge of public health worldwide, benefits and harms related to each CAM intervention are frequently disputable, which urges relevant researchers and academic societies to conduct rigorous clinical trials and to support information for medical decision with evidence-based knowledge through reputable clinical guidelines. One of the major factors that may be inhibiting referrals of CAM treatments by biomedical doctors is the absence of appropriate information related to CAM interventions [1]. In this sense, this current safety guideline on the Gua sha (press-stroking) and Ba guan (cupping) by Nielsen et al. deserves a passionate welcome, even though it seems to have room for improvement, especially in the field of cupping [2].

Compromising with reality inevitably, recently published addendum of this guideline added a process for disinfection or sterilization of cupping devices, which might retract clinical importance of this guideline [3]. Although recommended sterilization process might be effective in preventing most unnecessary adverse events related to wet-cupping, it seems quite clear that all the blood-borne viral infection cannot be blocked perfectly with it. Single use of cupping device is the best way we need to pursue, and it is not an impossible measure practically. In this letter, we want to show a good example of dissemination of single-use, disposable cupping cup through the government policy in Korea.

Korean National Health Insurance Service has reimbursed the material costs of single-use, disposable cupping cups for wet-cupping treated by doctors of Korean Medicine (KM) abiding by the decision of National Health Insurance Policy Deliberative Committee, Ministry of Health \& Welfare Since 2012. Presently, there are seven companies producing disposable cups after obtaining approval from the ministry (Table 1). Any licensed doctors of KM who use these products for wet-cupping can get reimbursement from the service after easy registration in the website of Korean Health Insurance Review \& Assessment Service (http://www.hira.or.kr/). From our experience of clinical practice and trials, these single-use cups can be utilized very safely and any specific adverse events hardly occur [4].

Because there is not yet any survey result on the current state of utilization of disposable cupping in Korea, future related study will be necessary on the real usage of disposable cupping cups in KM clinics. But it seems to be that more and more doctors of KM move to using disposable cupping cups because they are safer than reused ones, and doctors do not need to pay for them. Patients who are prejudiced against the wet-cupping therapy for its unsanitary nature will participate in cupping treatment willingly in this situation. As several times used, sterilized blunt needles were thrown out by single-use, disposable needles for acupuncture treatment currently, single-use, disposable cupping cups will be 
TABLE 1: The list of authorized companies producing disposable cupping cups which can be reimbursed by National Health Insurance Service in Korea.

\begin{tabular}{|c|c|c|c|c|}
\hline Name & Materials & $\begin{array}{l}\text { Product sizes } \\
\text { (internal diameter, } \\
\mathrm{mm} \text { ) }\end{array}$ & Website & First approval date \\
\hline SeongHo trade & Polystyrene, silicone & $\begin{array}{l}50,45,37,28,22 \text {, and } \\
15\end{array}$ & http://www.9988.tv/ & Jan. 1, 2012 \\
\hline DongBang Acupuncture Inc. & Polypropylene, silicone & $49,45,37,28$, and 21 & http://www.dbneedle.com/ & Jan. 1, 2012 \\
\hline LEADERS MEDITEC & Polystyrene, silicone & $53,45,29$, and 22 & Not available & Jan. 1, 2012 \\
\hline DEmedical & Polystyrene, plastic, and silicone & $50,40,31$, and 21 & http://www.demedical.co.kr/ & Feb. 1, 2012 \\
\hline Haneng Lim Seo Won Medical & Polystyrene & Unidentified & http://www.hlmedical.com/ & Sep. 1, 2012 \\
\hline Hihealth corp. & Polystyrene & $45,39,30,25$, and 20 & http://www.hihealth.kr/ & Sep. 1, 2012 \\
\hline Goodpl & Polyethylene, silicone & Unidentified & http://www.goodpl.kr/ & Jan. 1, 2013 \\
\hline
\end{tabular}

a market leader in future. Government policy can also promote this process as it is working in Korea.

\section{Conflict of Interests}

The authors declare that they have no conflict of interests.

\section{Acknowledgment}

The work was supported by a grant from Kyung Hee University in 2014 (KHU-20140709).

\section{References}

[1] A. Nielsen, B. Kligler, and B. S. Koll, "Addendum: safety standards for Gua sha (press-stroking) and Ba guan (cupping)," Complementary Therapies in Medicine, vol. 22, no. 3, pp. 446448, 2014.

[2] A. Nielsen, B. Kligler, and B. S. Koll, "Safety protocols for Gua sha (press-stroking) and Baguan (cupping)," Complementary Therapies in Medicine, vol. 20, no. 5, pp. 340-344, 2012.

[3] K. D. Shere-Wolfe, J. C. Tilburt, C. D’Adamo, B. Berman, and M. A. Chesney, "Infectious diseases physicians' attitudes and practices related to complementary and integrative medicine: results of a national survey," Evidence-Based Complementary and Alternative Medicine, vol. 2013, Article ID 294381, 8 pages, 2013.

[4] T.-H. Kim, J. W. Kang, K. H. Kim et al., "Cupping for treating neck pain in video display terminal (VDT) users: a randomized controlled pilot trial," Journal of Occupational Health, vol. 54, no. 6, pp. 416-426, 2012. 


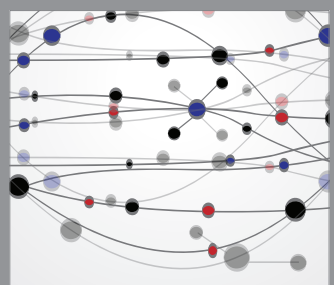

The Scientific World Journal
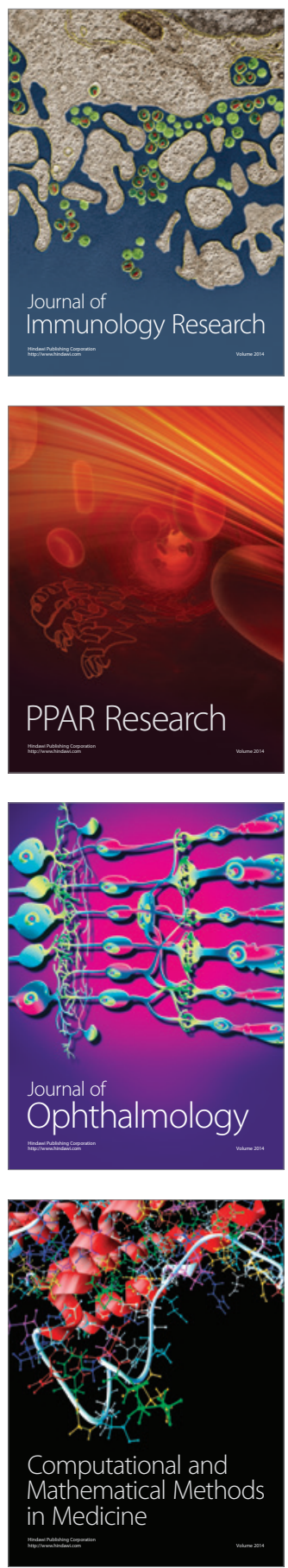

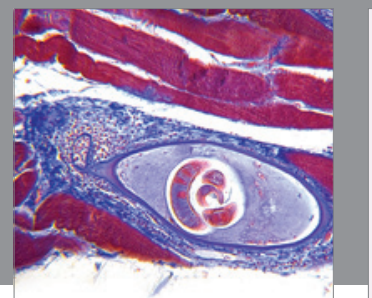

Gastroenterology

Research and Practice
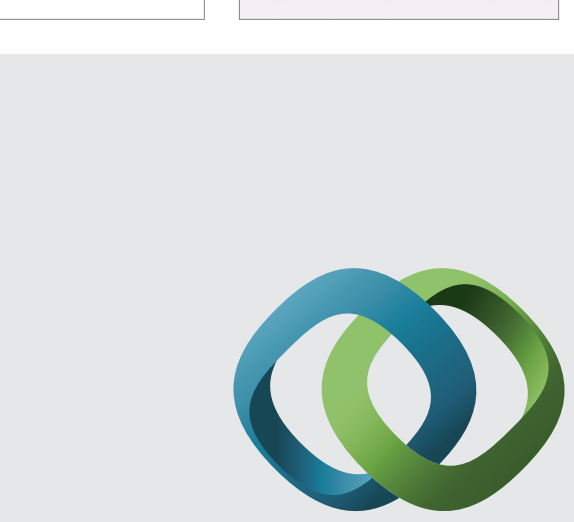

\section{Hindawi}

Submit your manuscripts at

http://www.hindawi.com
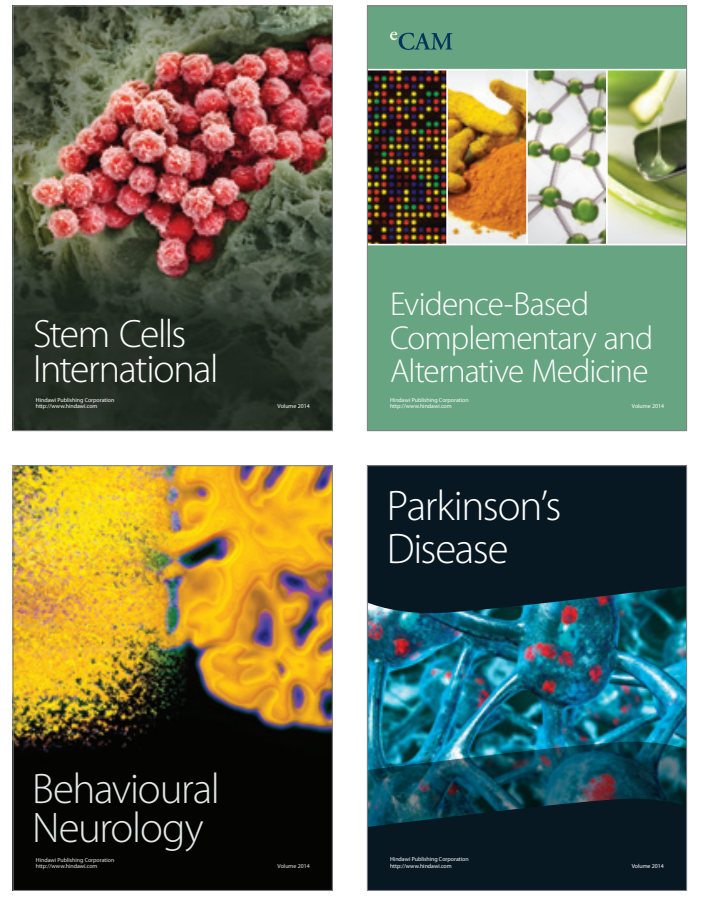
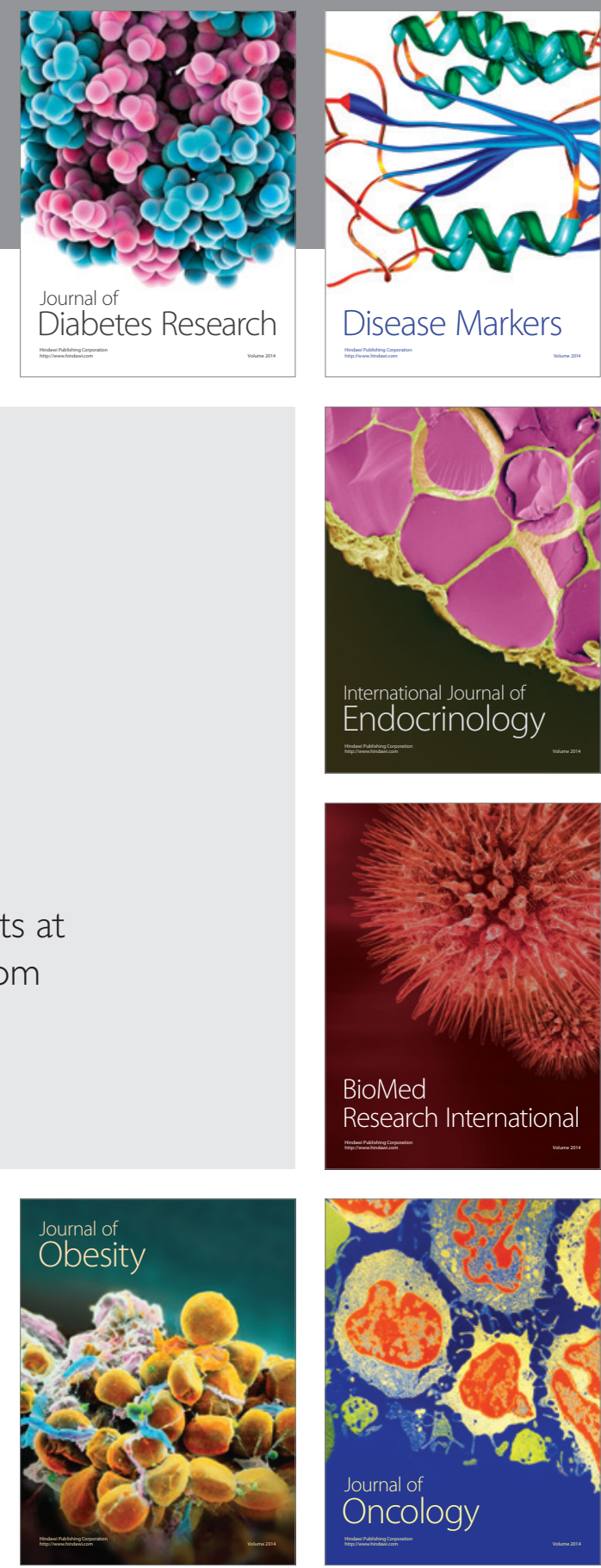

Disease Markers
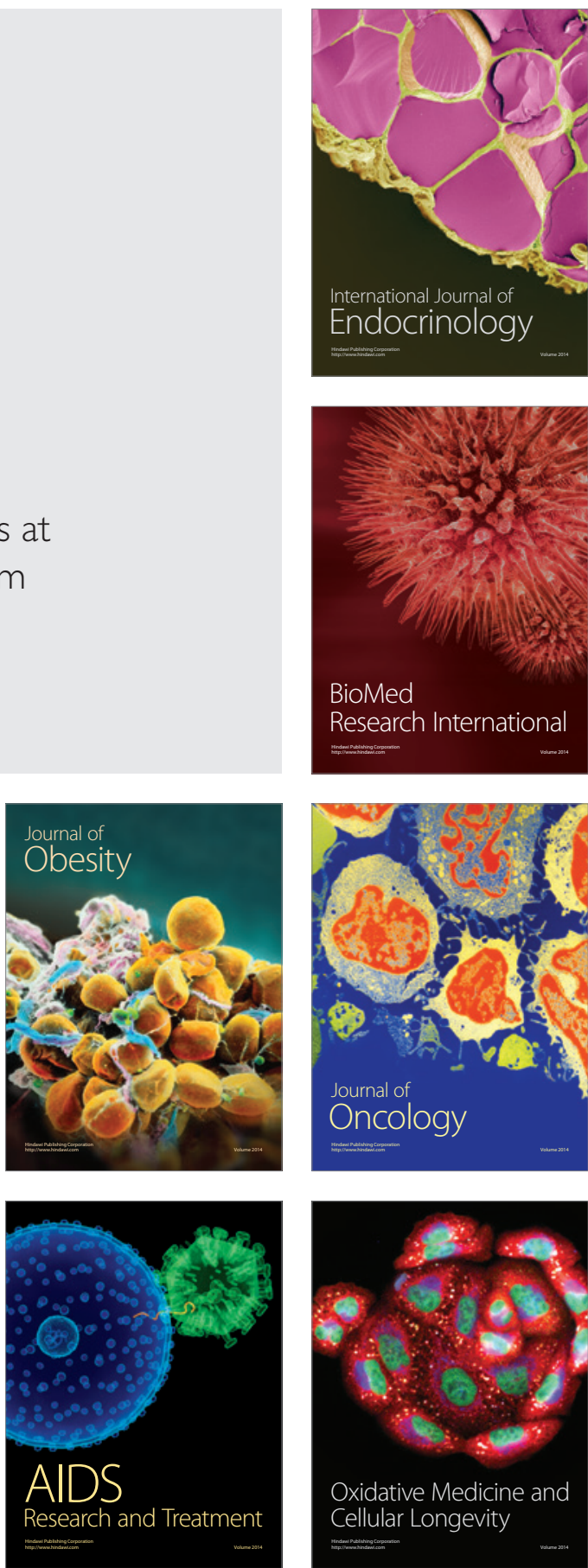